\title{
PERCEPÇÕES AMBIENTAIS E TRILHAS ECOLÓGICAS: CONCEPÇÕES DE MEIO AMBIENTE EM ESCOLAS DO MUNICÍPIO DE SOURE, ILHA DE MARAJÓ (PA)
}

\author{
Silas Moura Repolho ${ }^{1}$ \\ Dayana Natacha Souza Campos² \\ Ana Cláudia Caldeira Tavares-Martins ${ }^{3}$ \\ Davison Márcio Silva de Assis ${ }^{4}$ \\ Altem Nascimento Pontes ${ }^{5}$
}

Resumo: Este artigo relata as concepções ambientais de estudantes do ensino fundamental menor em duas escolas do município de Soure-PA e a contribuição de uma trilha ecológica como recurso pedagógico para ampliação de suas concepções. O estudo foi conduzido em quatro etapas, a saber: aplicação de mapas mentais para avaliação dos conhecimentos prévios, palestra sobre a importância dos manguezais, caminhada em uma trilha ecológica e aplicação de mapas mentais para verificação das concepções adquiridas. A prática possibilitou aos alunos o incremento de suas concepções a respeito do meio ambiente, o qual era muitas vezes visto somente como natureza intacta onde o ser humano não era parte integrante.

Palavras-chave: Educação Ambiental; Mapas mentais; Trilhas interpretativas.

${ }^{1}$ Licenciado em Ciências Naturais-Biologia UEPA. E-mail: silasmoura.17@gmail.com 2 Licenciada em Ciências Naturais-Biologia UEPA. E-mail: dayanacampos@hotmail.com

3 Orientadora. Doutora em Botânica. Professora e Pesquisadora do Programa de Pós-Graduação em Ciências Ambientais da Universidade do Estado do Pará UEPA/PPGCA. E-mail: tavaresmartins7@gmail.com

${ }^{4}$ Biólogo. Mestrando em Ciências Ambientais, UEPA/PPGCA. E-mail: davison-assis@hotmail.com

5 Doutor em Ciências Físicas. Professor e Pesquisador do Programa de Pós-Graduação em Ciências Ambientais da Universidade do Estado do Pará. E-mail: altempontes@hotmail.com 


\section{Introdução}

Desde que a Terra passou a ser habitada pelo homem, a humanidade vem demonstrando pouco ou nenhum cuidado com a biodiversidade, em decorrência do consumismo desenfreado que tem gerado inúmeras mudanças negativas no meio ambiente (SILVA, 2016). Um exemplo disso é a exploração insustentável das florestas tropicais nativas da Amazônia, causando perda da sua cobertura florestal e diversidade de espécies, antes mesmo que se tenha o conhecimento dessa riqueza natural (JARDIM; QUADROS, 2016).

Diante do uso insustentável dos recursos naturais, Silva e Rufino (2016) relataram que um dos caminhos para que tais perturbações diminuam ou até mesmo acabem é a Educação Ambiental. Essa proposta também é sugerida por Monteiro e Monteiro (2017), que a definem como uma estratégia que produz efeitos qualitativos na construção de novos valores e conhecimentos ambientais.

Dentro dessa ótica, as questões relativas ao meio ambiente apresentamse como um assunto que requer máxima urgência no que diz respeito à sua conservação (CARNEIRO et al., 2016). Neste sentido, o desenvolvimento de projetos educacionais voltados para o enfoque ambiental, podem sensibilizar os alunos na mudança de valores, comportamentos, sentimentos e atitudes (SORRENTINO; TRAJBER, 2007). A curiosidade dos educandos e abertura cognitiva ao conhecimento fazem com que estes assimilem conteúdos com maior facilidade, transformando-se em agentes multiplicadores de conhecimento (OLIVEIRA, 2006).

Antes da aplicação de qualquer projeto voltado à Educação Ambiental, faz-se necessário conhecer quais as concepções os alunos acumularam ao longo de suas experiências, pois elas podem influenciar na execução das ações educativas (ESTEVAM; GAIA, 2017).

No propósito de se compreender quais as concepções foram construídas pelos alunos ao longo de sua existência, os mapas mentais surgem como ferramentas que expressam o produto de experiências do indivíduo em contato com o meio (LANDIM-NETO; DIAS, 2011). Caracteriza-se por ser uma estratégia de anotação de informações de maneira não linear, ou seja, elaborado em forma de teia, onde a ideia principal é colocada no centro de uma folha de papel branco (OLIVEIRA; CEARENSE, 2006).

Pesquisas que objetivam relatar e/ou avaliar a concepção ambiental dos indivíduos podem constituir-se como excelentes instrumentos educativos e transformadores, desde que propiciem condições para a reflexão do próprio indivíduo (VENTURIERI; SANTANA, 2016). Uma das principais vantagens da ampliação das concepções ambientais está no desenvolvimento de ações mais sustentáveis na relação sociedade-natureza, garantindo condições necessárias para a sobrevivência das gerações futuras (MARIA; ZANON, 2012).

A região amazônica, sendo um ambiente megadiverso, constitui-se como um celeiro para o desenvolvimento de processos de aprendizagem eficazes (ARAÚJO et al., 2011). Nesse contexto, o arquipélago marajoara

revista brasileira educação ambiental 
situado no estado do Pará, faz parte do território amazônico e é considerado como uma área de proteção ambiental, o qual apresenta grande potencial para o desenvolvimento de atividades educacionais ao ar livre (MENDES et al., 2016). Dentre os diversos espaços de educação não formal, as trilhas ecológicas apresentam grande parte de sua área preservada e podem ser utilizadas em atividades formativas de Educação Ambiental (NELSON, 2012).

Diante dessas considerações, o objetivo desta pesquisa foi demonstrar o como uma trilha ecológica como recurso pedagógico pode incrementar as concepções ambientais de estudantes do ensino fundamental menor em duas escolas do município de Soure, na ilha do Marajó, Pará, Brasil.

\section{Metodologia}

A pesquisa utilizada neste trabalho é do tipo pesquisa-ação, descrita por Gil (2002) como aquela que possui base empírica, que é concebida e realizada em estreita associação com uma ação ou resolução de um determinado problema coletivo, no qual os pesquisadores e participantes representativos da situação ou do problema estão envolvidos de modo cooperativo e participativo.

Nesse sentido participativo, o estudo foi realizado no âmbito do Projeto Manguezal: conhecendo e protegendo, de iniciativa do Instituto Chico Mendes de Conservação da Biodiversidade (ICMBio), o qual visava desenvolver ações educativas que propiciassem a conservação do manguezal, por meio da sensibilização e informação da população local. Neste contexto, a Universidade do Estado do Pará (UEPA) colaborou com a inserção da teoria das concepções como forma de tornar essa atividade lúdica, associando aos conteúdos teóricos as atividades práticas, para que o aluno valorize os ecossistemas naturais, e observe sua importância para a manutenção do equilíbrio ambiental (COPATTI et al., 2010).

Este estudo teve como público-alvo os alunos de duas escolas da rede municipal situadas no município de Soure, na ilha de Marajó, Pará, à saber: Escola Municipal de Ensino Fundamental Profa. Antônia Tavares, e a Escola Municipal de Ensino Fundamental Raimundo da Silva Ramos. A pesquisa ocorreu nos meses de agosto e setembro de 2015, com quatro turmas do $5^{\circ}$ ano do ensino fundamental, com alunos de faixa etária de 10 a 16 anos. A escolha desta série deu-se pelo fato de ser considerado um período de transição na vida do indivíduo, com o amadurecimento para adolescência. É uma etapa de passagem do conhecimento escolar, na qual os saberes de raízes familiares recebem, com maior frequência, influências do meio (MENGHINI, 2005).

O presente estudo foi dividido em quatro etapas: a. aplicação de mapas mentais para avaliação dos conhecimentos prévios, b. palestra sobre a importância dos manguezais, c. caminhada na trilha ecológica e d. aplicação de mapas mentais para avaliação das concepções adquiridas. Cada atividade ocorreu em dias diferentes e durante o horário de aula, e foi desenvolvida com 
uma turma por vez, com no máximo 23 alunos. Essa estratégia de aplicação de mapas mentais antes e após as atividades educativas foi baseada na metodologia de Pinheiro et al. (2016), que também utilizou esse método para avaliar as ressignificações sobre Natureza, Meio Ambiente e Educação Ambiental de alunos do ensino fundamental.

\section{Aplicação de mapas mentais e questionários para avaliação dos conhecimentos prévios}

Foram aplicados mapas mentais para saber o que os alunos concebiam sobre meio ambiente. Priorizou-se a construção de mapas na horizontal para proporcionar maior visibilidade, descritos apenas com palavras chaves e ilustrados com imagens, ícones e muitas cores.

Baseado em Sauvé (2005), com modificações de Santos e Sato (2002) analisou-se sete concepções: 1. o meio ambiente como Natureza (para apreciar, para respeitar, para preservar); 2. o meio ambiente como Recurso (para gerir, para repartir); 3. como Problema (para prevenir, para resolver); 4. como Sistema (compreender e decidir melhor); 5. Meio de Vida (para conhecer, para organizar); 6. como Biosfera (onde viver junto e a longo prazo) e 7. como Projeto Comunitário (em que se empenhar ativamente).

Foi repassado a cada aluno uma folha de papel tamanho A4 com a seguinte pergunta: Para você o que significa meio ambiente? E dado o seguinte comando: Faça um desenho que o retrate. Além do papel foi disponibilizado aos alunos, lápis de cor, lápis preto comum e giz de cera.

Os alunos levaram aproximadamente 45 minutos para entregar suas produções que, neste estudo, são designados como mapas mentais (LANDIMNET; DIAS, 2011). A confecção permitiu de forma livre a expressão de tudo o que eles entendiam por fazer parte do meio ambiente, inclusive a inserção ou não de elementos da natureza ou pontos de identificação ambiental.

Juntamente com a folha de papel para os mapas foi fornecido um questionário semiestruturado com perguntas objetivas e subjetivas que versavam sobre seus entendimentos a respeito do meio ambiente. Segundo Campos et al. (2011) esse mecanismo pode avaliar o conhecimento que os alunos têm de um determinado lugar, estimulá-los a interpretar os problemas sociais e ambientais que estão especializados nos mapas e melhorar a aprendizagem dos conteúdos em sala de aula.

\section{Palestra sobre a importância dos manguezais}

$\mathrm{Na}$ segunda etapa da pesquisa, por ocasião do Projeto Manguezal os alunos participaram de uma palestra interativa, apresentada em PowerPoint, dando livre acesso a perguntas e curiosidades, tendo como principais conceitos abordados o ciclo reprodutivo do caranguejo-uçá Ucides cordatus (Linnaeus, 1763), o ecossistema de manguezal e sua biodiversidade, usos da área de mangue e Unidade de Conservação na Reserva Extrativista Marinha de Soure.

revista brasileira educação ambiental 
Durante a palestra os estudantes foram estimulados a pensar na importância do manguezal em suas vidas, na cultura local e quais os impactos (positivos e negativos) de suas ações sobre este. Após a palestra foram convidados a participar de uma atividade lúdica chamada "passa ou repassa ambiental", um jogo de perguntas e respostas pertinentes aos assuntos abordados. A dinâmica consistiu em dividir a turma em dois grandes grupos e fazer perguntas para um representante de cada, referente à fauna e flora dos manguezais abordada anteriormente na palestra.

Os alunos tiveram um tempo de trinta segundos para formular a resposta, podendo consultar a equipe. Caso o aluno errasse a resposta, o colega (de outra equipe) tinha direito de tentar responder corretamente também com o tempo de 30 segundos, caso ocorresse erro a pontuação era lançada para a equipe adversária. Acertando a equipe ganhava pontos, ao final ganhava a equipe que obtivesse a maior pontuação.

\section{Caminhada na trilha ecológica}

Os estudantes foram encaminhados a trilha ecológica localizada na praia da Barra Velha, município de Soure, onde atravessaram um ambiente de manguezal sobre uma ponte de aproximadamente $150 \mathrm{~m}$. Ao chegar na entrada, cada turma foi dividida em duas equipes, com o objetivo de manter uma média de 10 alunos por vez na caminhada.

Ao longo do percurso foram distribuídas 10 placas e três banners em locais sombreados e de fácil fixação em nível aproximado da altura das crianças (Figura 1). Nas placas estavam ilustrados fauna e flora típicos dos manguezais do município, bem como informações sobre a morfologia, habitat, biologia reprodutiva e as principais ameaças sofridas por aquela espécie.

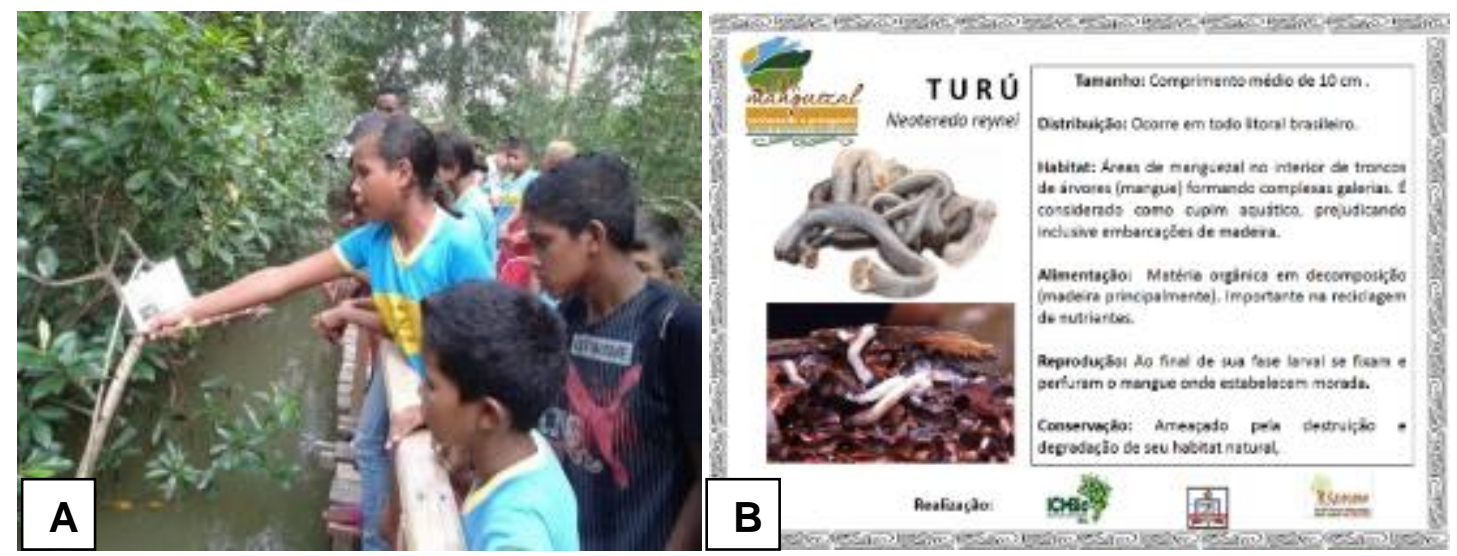

Figura 1: A - Alunos observando a placa. B - Ampliação da placa e as informações sobre as espécies ocorrentes nos manguezais

Fonte: A. Tavares-Martins 2015, B. ICMBio, 2014 
Cada banner, foi elaborado com imagens que reportavam ideias que faziam alusão às concepções sobre meio ambiente expressando aspectos da biodiversidade, ambientes naturais e ações antrópicas (Figura 2). Os mesmos foram fixados utilizando-se o mesmo critério das placas, em três locais distintos: início, meio e final da trilha, sendo que cada local de parada para observação do mesmo foi denominada de estação. Quanto a este modelo metodológico, Fritzen et al. (2011) afirmam que como recurso pedagógico, geralmente é estabelecido um roteiro prévio para a caminhada, através de um passeio autoguiado com paradas estratégicas, para que seja possível o contato direto com a natureza, o que foi aplicado nesta pesquisa.

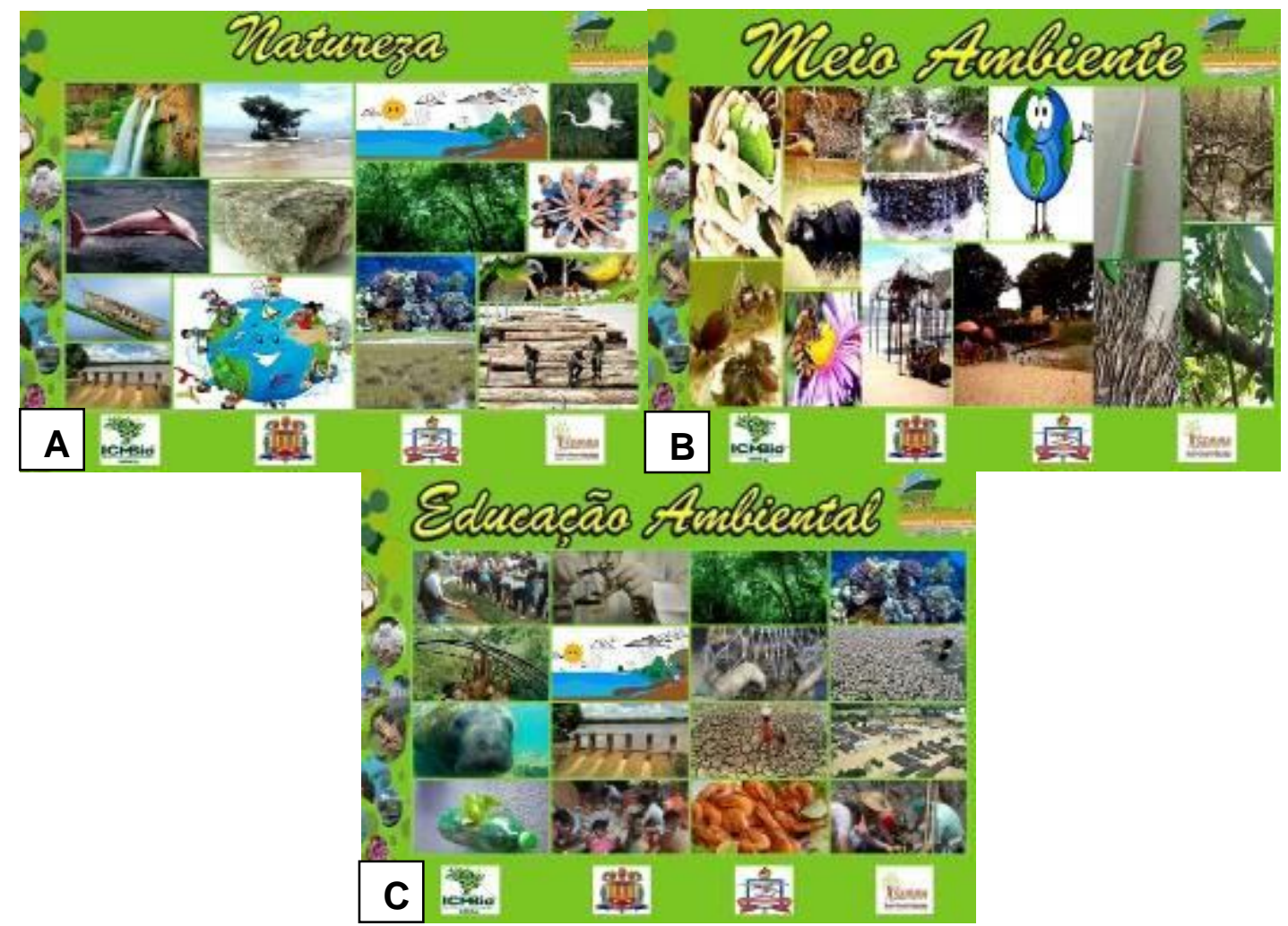

Figura 2: Banners utilizados na trilha ecológica. A - Representação da primeira estação. BRepresentação da segunda estação. C - Representação da terceira estação

Fonte: A. Tavares-Martins 2015

Os grupos realizaram três paradas nas estações, para reflexão, onde foi realizado um aprofundamento da sensibilização, visando chamar a atenção para a fragilidade do ecossistema, os impactos da ação dos seres humanos, a biodiversidade e sua flutuação dinâmica e as atitudes ecológicas. Segundo Kaercher (2002), é preciso fazer com que o aluno perceba qual a importância do espaço, na constituição de sua individualidade e da(s) sociedade(s) de que ele faz parte (escola, família, cidade, país etc.).

No primeiro banner, localizado na primeira estação, foram abordados assuntos referentes à natureza e qual a sua importância, e na ocasião as equipes se autodenominaram com um termo relativo à temática trabalhada naquela parada, por exemplo: Equipe Caranguejo.

revista brasileira educação ambiental 
O segundo banner, localizado na segunda estação, demarcava uma área próximo ao igarapé, onde foram explanados assuntos sobre o meio ambiente, a sua influência no ser humano e algumas formas de relações ecológicas, sendo desenvolvida a segunda atividade da gincana denominada: "grito de guerra ambiental", no qual cada grupo preparou uma frase que demonstrava compreensão, comprometimento e preocupação com as questões ambientais.

$\mathrm{Na}$ última estação, localizada na saída da trilha, foi abordado a respeito de sustentabilidade e impactos ambientais. As crianças puderam observar o ambiente de restinga e a praia, onde a paisagem mostrava a maior influência do ser humano no ambiente, principalmente pela quantidade de resíduos sólidos encontrados. Adicionalmente, para reforçar o aspecto lúdico do projeto foi aplicada uma gincana onde os alunos eram estimulados cantar um "grito de guerra" criado por eles. Posteriormente, participavam de um jogo de perguntas e respostas relacionado às placas, banners e ao ambiente de manguezal (Figura 3).

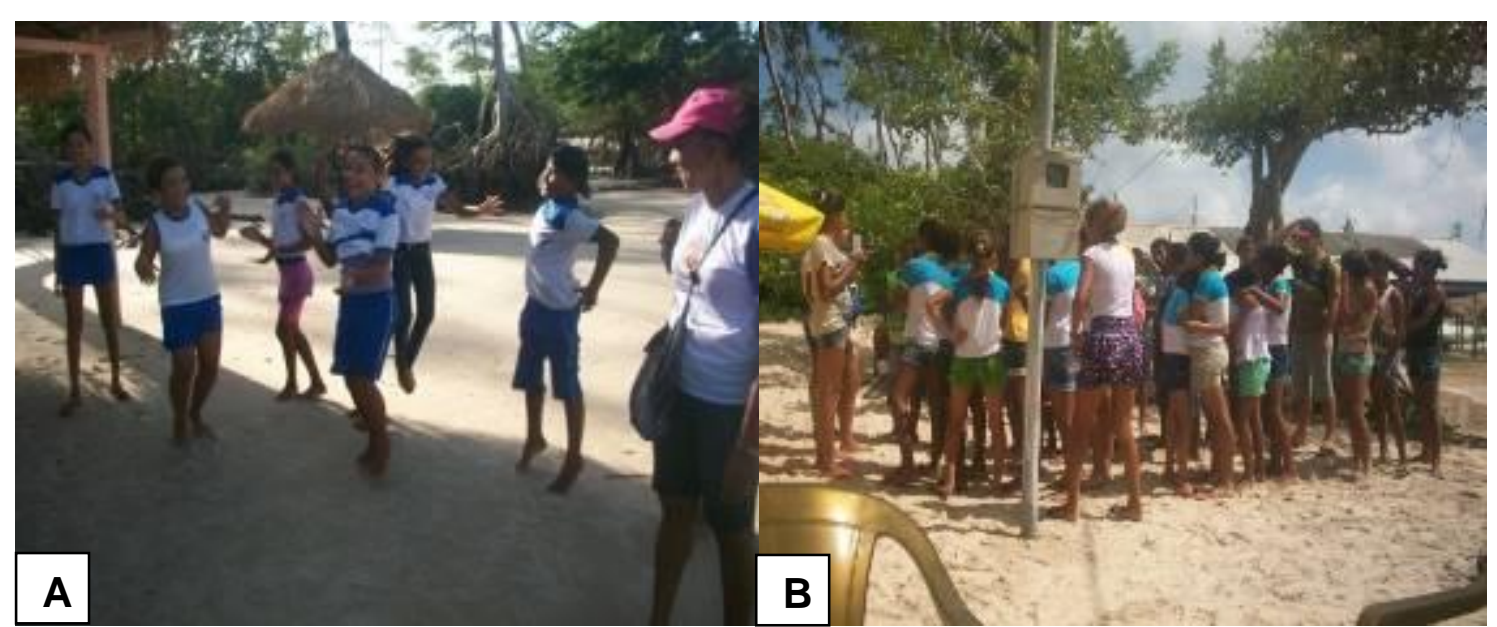

Figura 3: Realização de atividades lúdicas ao final da trilha ecológica. A- Escola "Prof. Antônia Tavares". B- Escola "Raimundo Silva Ramo"

Fonte: Tavares-Martins et al., 2015

\section{Mapas mentais para avaliação das concepções adquiridas}

A última etapa consistiu no retorno às turmas, após cerca de 15 dias para um novo levantamento de mapas mentais buscando observar possíveis incrementos nas concepções dos alunos e, consequentemente, o efeito da trilha como ferramenta pedagógica. 


\section{Resultados e discussão}

\section{Avaliação prévia}

Segundo a Tabela 1, observa-se que os alunos mesmo já tendo experiência com a educação ambiental $(69,3 \%)$, sentindo-se parte integrante do meio ambiente $(88,0 \%)$ e entendendo este apenas como meio de sustentação $(61,8 \%)$ não veem a necessidade de conservá-lo $(78,6 \%)$. Esse resultado contrasta com a própria afirmativa deles sobre a preocupação com o meio ambiente $(85,4 \%)$, pois não relacionam a continuidade dos recursos com a necessidade de se conservar.

Tabela 1: Porcentagem das respostas do questionário entregue aos alunos.

\begin{tabular}{l|cc}
\hline \multicolumn{1}{c}{ PERGUNTAS } & SIM (\%) & NÃO (\%) \\
\hline Você já teve práticas de educação ambiental em sua escola? & 69,3 & 30,7 \\
Sua escola realiza excursões em campo? & 42,6 & 57,4 \\
Na sua opinião, você acha que faz parte do meio ambiente? & 88,0 & 12,0 \\
Você se preocupa com o meio ambiente, e as gerações futuras? & 85,4 & 14.6 \\
Você vê o meio ambiente como um lugar para ser respeitado e apreciado? & 21,4 & 78,6 \\
Você vê o meio ambiente como meio de sustentação? & 61,8 & 38,6 \\
Você gosta de estudar o meio ambiente ao seu redor? & 88,0 & 12,0 \\
Você gosta de realizar atividades envolvendo reciclagem? & 85,4 & 14,6 \\
\hline
\end{tabular}

Fonte: Autores, 2017.

Nas concepções sobre meio ambiente, os alunos 0 entendem predominantemente como natureza $(42,7 \%)$, seguido de problema $(18,7 \%)$, meio de vida $(24,0 \%)$, sistema $(5,3 \%)$, projeto $(8,0 \%)$ e recurso $(1,3 \%)$, evidenciado na Tabela 2.

Tabela 2: Porcentagem das percepções de antes da realização da trilha

\begin{tabular}{ccc}
\hline $\begin{array}{c}\text { PERCEPÇOES DE ANTES DA } \\
\text { PALESTRA E TRILHA }\end{array}$ & ALUNOS & PORCENTAGEM \\
\hline Natureza & 32 & $42,7 \%$ \\
Problema & 14 & $18,7 \%$ \\
Sistema & 4 & $5,3 \%$ \\
Projeto Comunitário & 6 & $8,0 \%$ \\
Recurso & 1 & $1,3 \%$ \\
Meio de Vida & 18 & $24,0 \%$ \\
Biosfera & 0 & $0,0 \%$ \\
\hline
\end{tabular}

Fonte: Autores, 2017

Seguindo o que preconiza Eisenlohr et al. (2013) sobre as trilhas possibilitarem o contato do homem com a natureza, neste trabalho ao longo da trilha interpretativa os alunos tiveram a oportunidade de observar o ecossistema relatado na palestra. $O$ contato com ambientes naturais pode gerar um sentimento de pertencimento ao ecossistema, sendo fundamental a 
conscientização dos visitantes e de todos aqueles que mantêm contato com locais de preservação, para entenderem que o ser humano é parte da natureza (PINHEIRO et al., 2010).

Dentro desse contexto, Silva et al. (2010) ressaltam que as trilhas ecológicas proporcionam a vivência prática dos conhecimentos teóricos, facilitando os processos de aprendizagem, dinamizando as práticas e estimulando estudantes a uma forma personalizada de aprendizagem, estimulando a contemplação e valorização dos atrativos naturais do local.

Quando questionados sobre o porquê de o caranguejo-uçá sair da sua toca e ficar andando pelo mangue?

Uma das respostas foi a do aluno "A":

"Ele sai para namorar e ter filhotes!"

Outra pergunta foi abordada: Por que a fêmea do caranguejo não pode ser capturada? O aluno "B" respondeu que:

"Porque é ela que carrega os ovos!"

Desta forma pode-se observar que o aluno, pode responder a partir de seu saber popular, típico da região, neste sentido Sousa (2009) acrescenta que através das percepções é possível conhecer o mundo cultural dos alunos que refletem o modo de vida deles no ambiente que convivem e observam.

Assim como os alunos A e B, os demais discentes conseguiram responder corretamente, pois o caranguejo-uçá sai das galerias onde se estabelecem para se reproduzir. Segundo Araújo e Calado (2008) e Wunderlich et al., (2008) a migração de Ucides cordatus conhecida popularmente por "andada" ou "carnaval do caranguejo" consiste no abandono de suas galerias e caminhada sobre o sedimento, para reprodução.

Ao refletirmos percebemos conforme Menghini (2005) que as trilhas interpretativas não existem somente para a comunicação de conceitos, mas também para compartilhar experiências que levem os visitantes a apreciar, entender, se sensibilizar, cooperar na conservação de um recurso natural e também a educar.

\section{Avaliação posterior}

As concepções identificadas através dos mapas analisados e comparados aos produzidos anteriormente à palestra e visita à trilha, estão apresentadas na Tabela 3. 
Tabela 3: Porcentagem das concepções de antes da realização da trilha

\begin{tabular}{ccc}
\hline $\begin{array}{c}\text { CONCEPÇÕES DEPOIS DA } \\
\text { PALESTRA E TRILHA }\end{array}$ & ALUNOS & PORCENTAGEM \\
\hline Natureza & 31 & $41,3 \%$ \\
Problema & 12 & $16,0 \%$ \\
Sistema & 6 & $8,0 \%$ \\
Projeto Comunitário & 6 & $8,0 \%$ \\
Recurso & 7 & $9,3 \%$ \\
Meio de Vida & 12 & $16,0 \%$ \\
Biosfera & 1 & $1,3 \%$ \\
\hline
\end{tabular}

Fonte: Autores, 2017

Dos 75 alunos que produziram os mapas mentais, 22 (29,3\%) não acrescentaram nenhuma outra concepção, ou seja, apresentaram a mesma categoria do mapa anterior, $53(70,7 \%)$ acrescentaram suas concepções e dois $(2,6 \%)$ apresentaram mais de uma categoria.

Comparando os resultados das concepções dos alunos antes e depois da realização das atividades, é possível evidenciar que as categorias que eles conseguiram acrescentar foram: Meio Ambiente como Recurso, Sistema e Biosfera, respectivamente. De acordo com os PCN's trabalhos com o tema Meio Ambiente nas séries iniciais devem contribuir para que os educandos tenham uma noção integradora e sistêmica (BRASIL,1997). Dentro dessa perspectiva, os resultados corroboram com essa orientação, visto que os alunos demonstraram compreender que o Meio Ambiente não deve ser visto só como Natureza, mas sim a partir de uma visão que integre diferentes concepções.

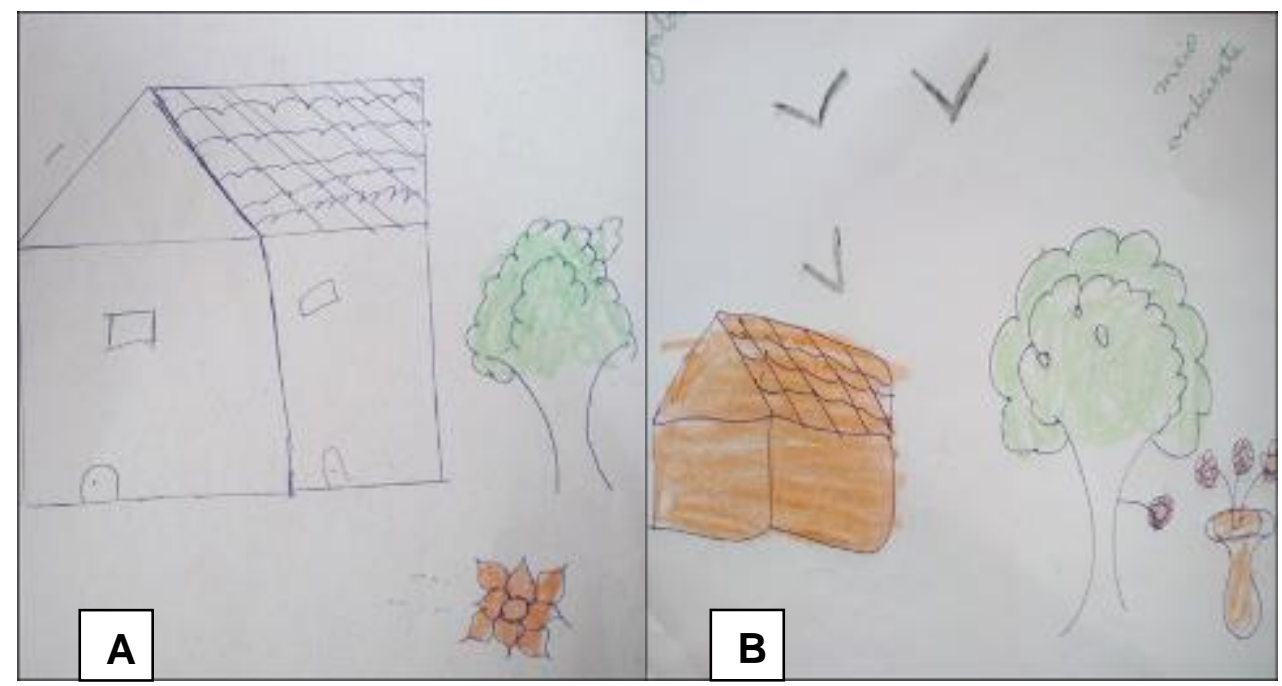

Figura 4: Mapa mental de um aluno caracterizado como Meio de Vida. A - antes da realização da trilha. B - após a realização da trilha

Fonte: Autores, 2017 
Analisando a Figura 4 nota-se que o aluno "C" não acrescentou nenhuma outra categoria, pois apresentou elementos semelhantes antes e após a palestra e a visita a trilha. Isso indica que, possivelmente, o aluno não estava pré-disposto a aprender, pois de acordo com Moreira (2011) a aprendizagem só ocorre se houver pré-disposição. Além disso, não se descarta a hipótese de que não se tenha dado a devida atenção que o mesmo necessitava para compreender os conceitos abordados ao longo da metodologia do trabalho.

$\mathrm{Na}$ Figura 5 observa-se que, inicialmente o aluno "D" compreendia o meio ambiente como Meio de Vida (5A), posteriormente, observa-se 0 acréscimo da concepção Problema (5B). Diniz e Lins (2012) ressaltam que os mapas podem ser utilizados para descrever o pensamento de uma pessoa sobre um problema. A esse respeito, Sauvé (2005) afirma que com os problemas socioambientais existentes é preciso reconstruir nosso sentimento de pertencer à natureza, para assim, minimizar os impactos negativos na mesma.

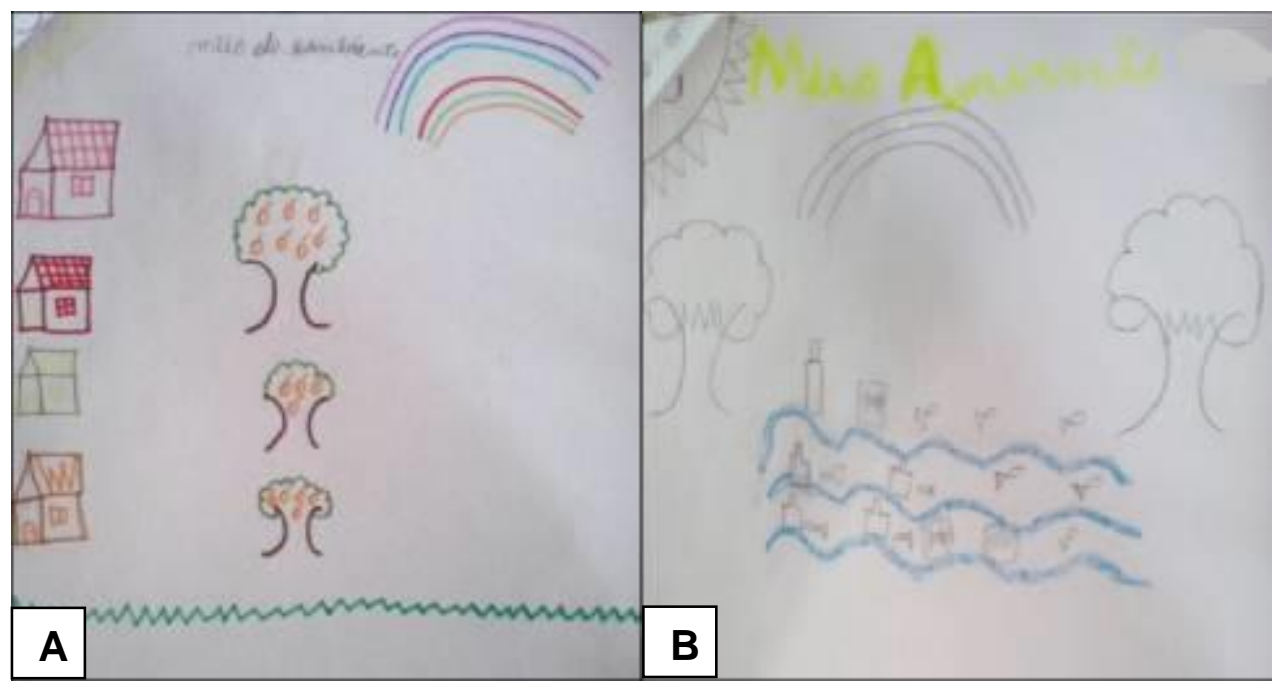

Figura 5: Mapa mental apresentando ampliação de concepção. A- concepção de Meio de Vida antes da visita a trilha. B - concepção como Problema após a visita a trilha

Fonte: Autores, 2017

Na Figura 6 o aluno "E" demonstrou que seu entendimento sobre meio ambiente expressa a concepção Projeto (6A), no qual chama a atenção ao destacar pessoas coletando lixo. Após a trilha observou-se que houve um incremento em suas concepções, caracterizando também o meio ambiente como Recurso (6B), pois ele retrata pessoas pescando, ou seja, retirando do ambiente recursos naturais. 


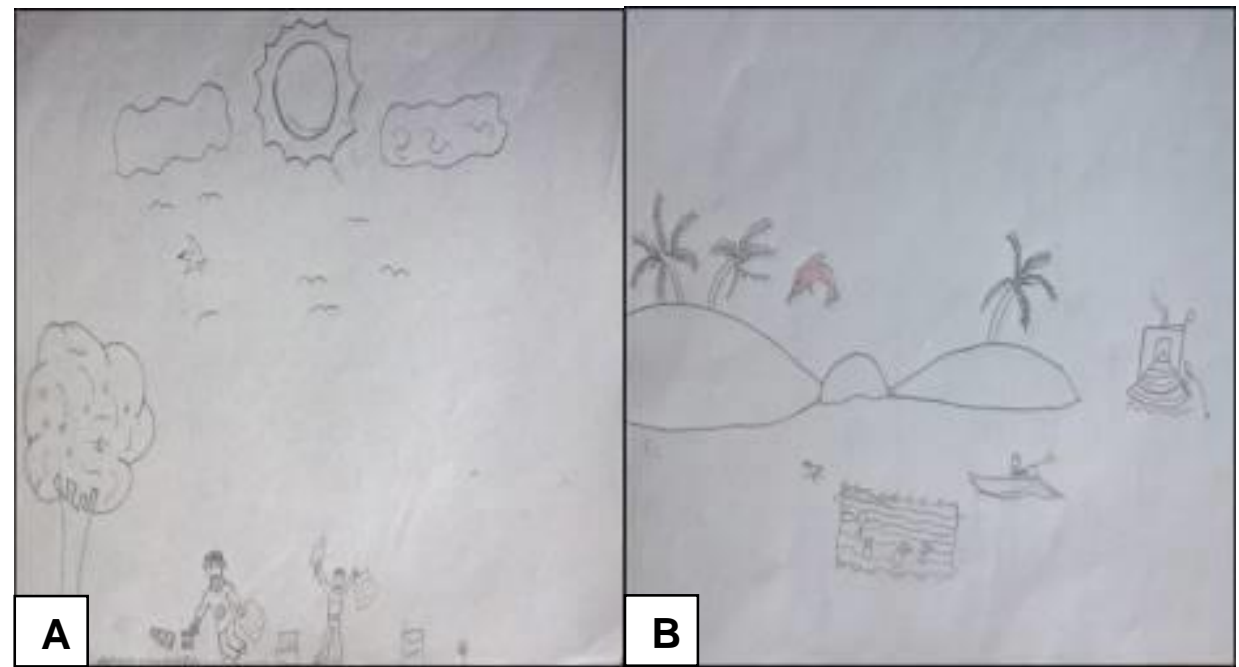

Figura 6: Mapa mental apresentado a ampliação de concepção. A - concepção de Projeto antes da visita a trilha. B - concepção como Recurso após a visita a trilha

Fonte: Autores, 2017

O Brasil possui inúmeros recursos naturais de fundamental importância para o mundo, desde ecossistemas até grande parte da água doce disponível para consumo humano, entretanto, a sensibilização pouco frequente da natureza como fonte de recursos esgotáveis tem levado a formas de exploração insustentáveis. Assim, ao considerar o meio ambiente também como recurso, faz-se necessário a promoção de práticas de conservação mais eficazes, uma vez que os recursos naturais são importantes para garantir a qualidade de vida das populações (BRASIL, 1997).

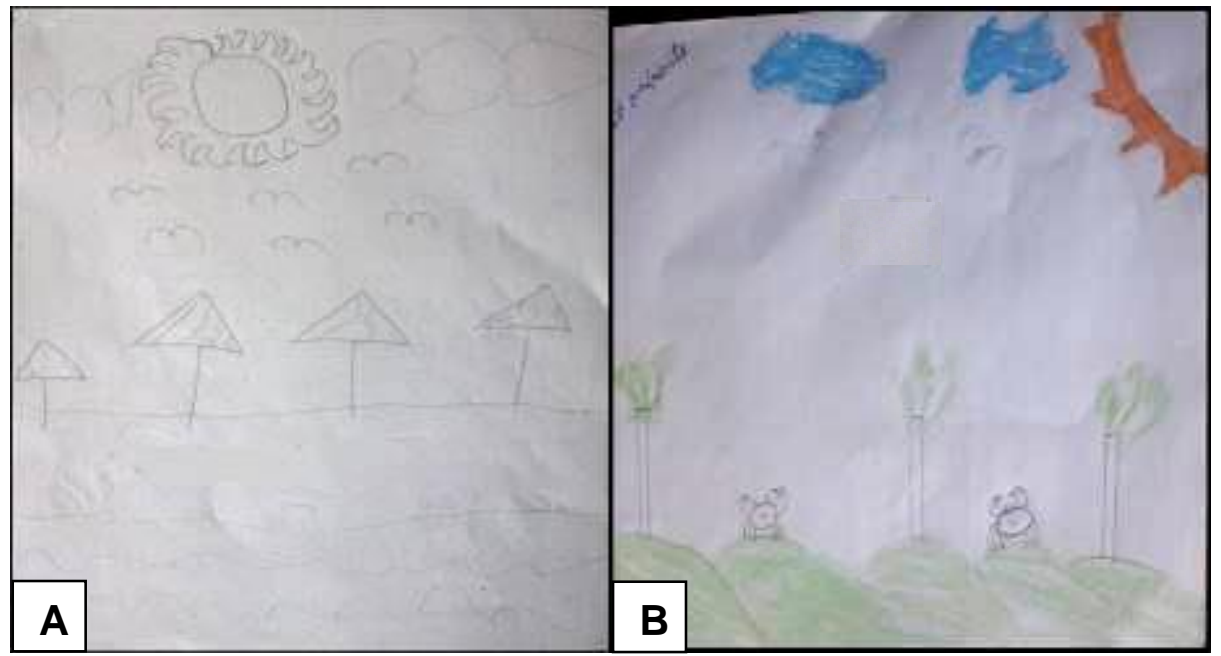

Figura 7: Mapa mental apresentando ampliação de concepção. A - concepção de Meio de Vida antes da visita a trilha. $\mathbf{B}$ - concepção como Natureza após a visita a trilha

Fonte: Autores, 2017

Na Figura 7 o aluno "F" apresenta sua concepção inicial como Meio de Vida (7A), ao retratar elementos como a praia, o sol as barracas, esta última expressando o ser humano como parte do mesmo. Após a trilha, pode-se 
perceber a concepção Natureza (7B), através das plantas e animais inseridos no mapa mental. Krzysczak (2016) reporta que a forma como o Meio Ambiente é percebido, relaciona-se com o modo de interação com este, e neste estudo isso é evidenciado no segundo mapa ao ser retratado o caranguejo (7B), o qual é um elemento típico da região que faz parte do seu cotidiano, e que também foi discutido na palestra e demonstrado na trilha.

Em Santos e Imbernon (2014), os autores perceberam que as concepções relatadas sobre Meio Ambiente não estão associadas a elementos que compõem o cotidiano dos alunos, pois os mesmos associam meio ambiente somente a ambientes florestados. No entanto, segundo o Sistema de Gestão Ambiental o meio ambiente é conceituado como: "circunvizinhança em que uma organização opera, incluindo-se ar, água, solo, recursos naturais, flora, fauna, seres humanos e suas inter-relações" (ABNT, 2004).

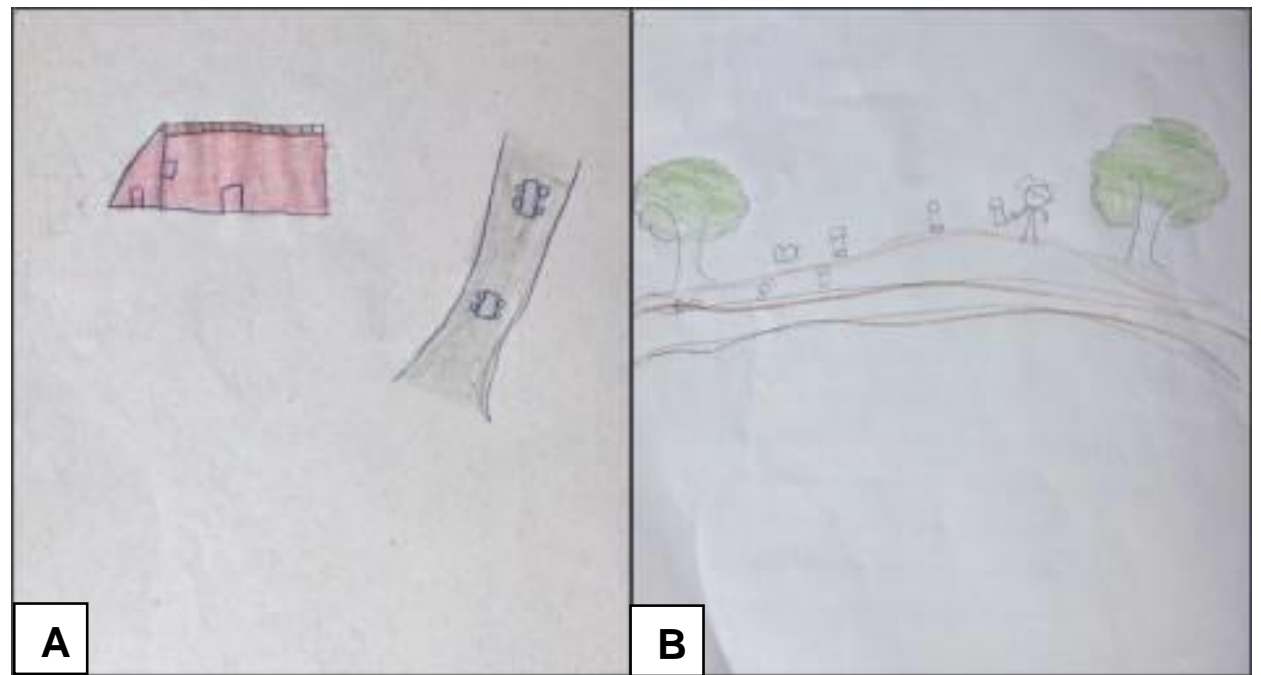

Figura 8: Mapa mental apresentando ampliação de concepção. A- concepção de Meio de Vida antes da visita a trilha. $\mathbf{B}$ - concepção como Problema após a visita a trilha

Fonte: Autores, 2017

Na Figura 8 nota-se que o aluno "G" antes da visita à trilha caracteriza o meio ambiente como Meio de Vida ao inserir elementos como sua casa, a rua e os carros, os quais pertencem ao cotidiano do mesmo (8A). Posteriormente, insere o lixo e a presença do ser humano como o causador da poluição, o qual demonstra que ele acrescentou a concepção Problema (8B).

Pereira e Curi (2012) ressaltam que a consciência sobre os problemas ambientais é algo recente, pois o mundo passou a se preocupar com os impactos gerados pelo mau uso dos recursos naturais, principalmente nas últimas décadas do século XX. Nesta perspectiva a Educação Ambiental deve atuar no sentido de informar as pessoas a respeito dos problemas ambientais, através da identificação e pesquisa de uma situação, diagnóstico, busca, avaliação e escolha de soluções (SAUVÉ, 2005). 


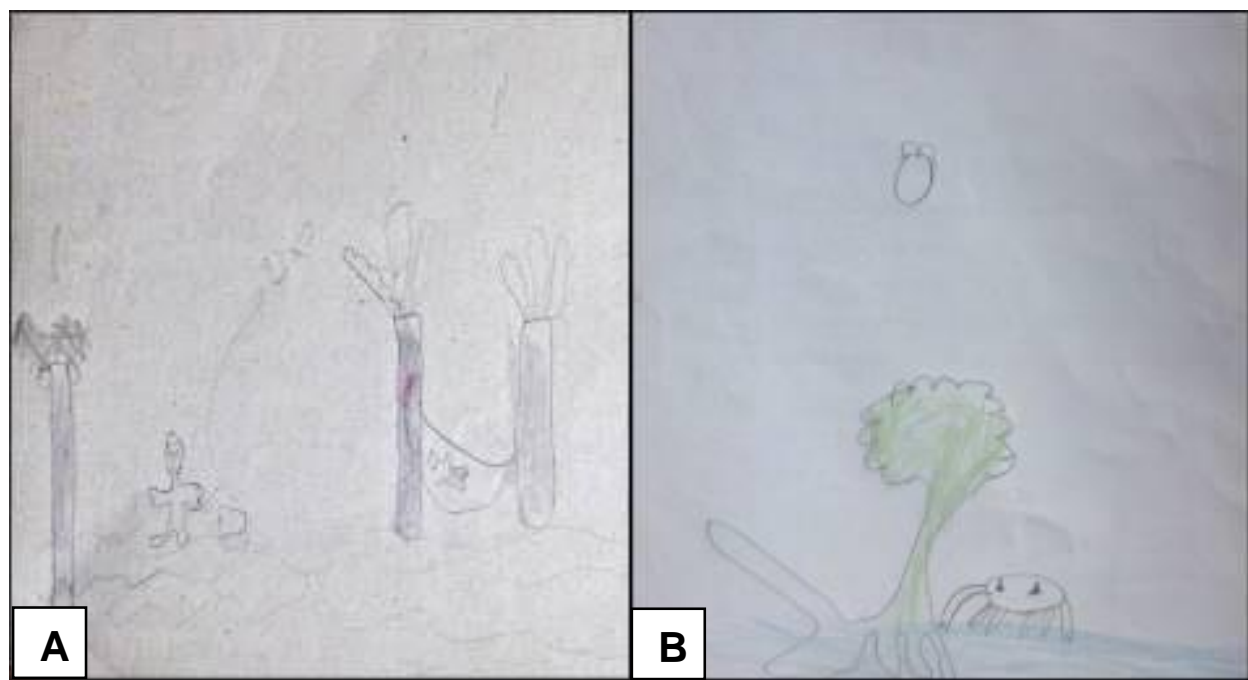

Figura 9: Mapa mental apresentando ampliação de concepção. A - concepção de Problema antes da visita a trilha. $\mathbf{B}$ - concepção como Natureza após a visita a trilha

Fonte: Autores, 2017

$\mathrm{Na}$ Figura 9, nota-se o acréscimo nas concepções do aluno " $\mathrm{H}$ ", ao verificar que antes da visita à trilha o estudante destaca o lixo e o ser humano, caracterizando o meio ambiente como Problema (9A). E no seguinte mapa mental classifica como Natureza (9B), abordando o que foi visto durante o percurso, como o mangue o caranguejo.

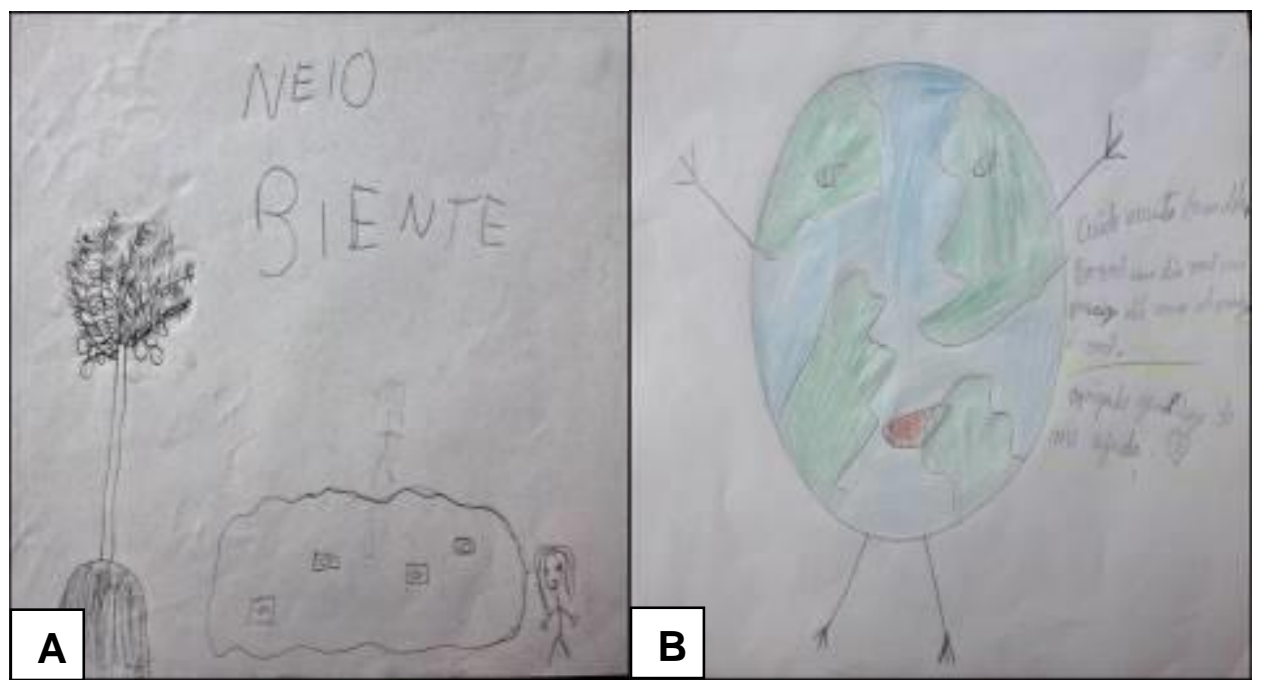

Figura 10: Mapa mental apresentando ampliação de concepção. A - concepção de Problema antes da visita a trilha. B - concepção como Biosfera após a visita a trilha

Fonte: Autores, 2017

Nas Figura 10 o aluno "l" demonstra sua concepção com a ilustração do ser humano e o lixo poluindo o mangue (10A), podendo assim ser classificado como Problema, ao apresentar a realidade e os eventuais problemas ambientais que o cerca. Este aluno ampliou sua concepção para Biosfera 
apresentando uma visão mais globalizada do meio ambiente (10B), levando a questão socioambiental à nível mundial.

De acordo com as definições de Reigota (2006), as representações sobre meio ambiente que podem ser identificadas no âmbito escolar são categorizadas em: globalizante, antropocêntrica e naturalista, em que a globalizante evidencia relações recíprocas entre a natureza e a sociedade. Partindo do ponto que o aluno "l" acrescentou em suas concepções uma visão global, acredita-se dessa forma que ele conseguiu conceber uma relação de reciprocidade entre homem e natureza, pois isso pode ser evidenciado no que foi escrito por ele no mapa de concepções adquiridas:

"Cuide muito bem dele, pois você um dia vai precisar dele como ele precisa de você".

Em seu trabalho Wollmann et al. (2015) concluíram que professores que apresentaram noções mais abrangentes de meio ambiente possuíam uma diversidade de estratégias em suas práticas docentes, bem como uma presente preocupação de se trabalhar de maneira interdisciplinar os temas voltados para Educação Ambiental. Deste modo o ensino de Educação Ambiental pautado em uma visão mais globalizada contribui para que alunos construam uma concepção mais integradora e abrangente sobre o tema.

Esses dados demonstram que a utilização da trilha produziu incremento nas concepções ambientais dos alunos. Neste sentido, Souza et al. (2012) destacam que as trilhas possibilitam também uma grande diversidade de eixos temáticos e abordagens ecológicas, tanto com finalidades acadêmicas para utilização no ensino fundamental, médio e superior.

Percebe-se a importante função dos mapas mentais na discussão dos conhecimentos em sala de aula, apresentando-se como um bom indicador de como são apreendidos os conceitos, categorias e conteúdo, o que elucida elementos primordialmente importantes na construção do conhecimento através de um processo dialógico (LADIM-NETO; DIAS, 2011).

\section{Conclusão}

A receptividade dos alunos em participar das tarefas foi positiva, onde foi possível observar contentamento com as interações propostas pelo projeto.

A utilização da trilha ecológica na Praia da Barra Velha, Soure, apresentou-se como um notável recurso didático para promover atividades voltadas à Educação Ambiental e incentivar a capacidade de observação e reflexão, pois ampliou a informação sobre o ambiente local e demonstrou sua importância, gerando sensibilização de alunos no início de sua adolescência.

Após a experiência em campo com os alunos da região notou-se que a 
incrementar suas concepções a respeito do meio ambiente a sua volta, o qual era muitas vezes visto somente como natureza intacta e o ser humano não era parte integrante.

O desenvolvimento do Projeto Manguezal aliado à proposta de inserção de contextos que conduziram os discentes a desenvolver outras concepções promoveu melhor reflexão sobre a relação de convívio entre os estudantes e o meio ambiente. Estas ações de iniciativa dos órgãos ligados à preservação e conservação da biodiversidade unidas aos preceitos das teorias da educação podem incentivar mudanças de hábitos e costumes que prejudiquem a fauna $e$ flora da região, visando a melhoria da qualidade de vida, tanto no presente quanto no futuro, de forma que garanta a sustentabilidade dos ambientes.

Portanto, as trilhas ecológicas como recurso pedagógico proporcionam melhores condições para a prática dos conhecimentos teóricos, com vistas a facilitar os processos de aprendizagem, dinamizando e estimulando os alunos, rumo a uma forma personalizada de aprendizagem. Esta experiência proporcionou oportunidades de incremento de suas concepções sobre o meio ambiente ampliando suas compreensões e sentimentos de pertencimento.

\section{Agradecimentos}

Aos analistas ambientais do Instituto Chico Mendes de Conservação da Biodiversidade (ICMbio-Soure) pela grande oportunidade de contribuir com suas ações educativas, pela autorização da realização desta pesquisa e pelo apoio logístico.

\section{Referências}

ABNT. NBR ISO 14001: Sistemas de Gestão Ambiental-Requisitos com orientações para uso. 2004. $27 \mathrm{p}$.

ARAÚJO, J.N.; SILVA, C.C.; TERÁN, A.F. A Floresta Amazônica. Um Espaço Não Formal em Potencial para o Ensino de Ciências. Anais do VIII ENPEC, 2011.

ARAÚJO, M.S.L.C.; CALADO, T.C.S. Bioecologia do Caranguejo-Uçá Ucides cordatus (Linnaeus) no Complexo Estuariano Lagunar Mundáu/Manguaba (CELMM), Alagoas, Brasil. Revista da Gestão Costeira Integrada, v. 8, n. 2, p. 169-181, 2008.

BRASIL. Secretaria de Educação Fundamental. Parâmetros curriculares nacionais: Meio Ambiente. Brasília-DF: MEC/SEF, 1997. 126p.

CAMPOS, G.O.; SILVA, R.T.; FARIA, F.S.R. Os mapas mentais no ensino fundamental: a percepção do espaço (um estudo aplicado ao $6^{\circ}$ ano da Escola Municipal Dr. Oswaldo Ferreira no Município de Santa Luzia, MG), 2011. 
CARNEIRO, B.S.; OLIVEIRA, M.A.S.; MOREIRA, R.F. EDUCAÇÃO AMBIENTAL NA ESCOLA PÚBLICA. Revista Brasileira de Educação Ambiental, v. 11, n. 1, p. 25-36, 2016.

COPATTI, C.E.; MACHADO, J.V.V.; BOSS, B. Uso de trilhas ecológicas para alunos do ensino médio em Cruz Alta - RS como instrumento de apoio a prática teórica. Educação Ambiental em Ação, ano 9, n. 34, 2010.

DINIZ, M.E.; LINS, M.P.E. Percepção e estruturação de problemas sociais utilizando mapas cognitivos. Produção, v. 22, n. 1, p. 142-154, 2012.

EISENLOHR, P.V.; MEYER, L. et al. Trilhas e seu papel ecológico: o que temos aprendido e quais as perspectivas para a restauração de ecossistemas? Hoehnea, v. 40, n. 3, p. 407-418, 2013.

ESTEVAM, C.S.; GAIA, M.C.M. Concepção ambiental na educação básica: subsídios para estratégias de educação ambiental. Revista Brasileira de Educação Ambiental, v. 12, n. 1, p. 195-208, 2017.

FRITZEN, R.I.; LIMA, V.M.R.; BORGES, R.M.R. Reconstituição Histórica de uma Trilha Ecológica no Contexto de uma Comunidade Escolar. Pontifícia Universidade Católica do Rio Grande do Sul. Porto Alegre, 2011.

GIL, A.C. Como elaborar projetos de pesquisa. 4. ed. São Paulo: Atlas, 2002. $175 \mathrm{p}$.

JARDIM, F.C.S.; QUADROS, L.C.L. Estrutura de uma floresta tropical dez anos após exploração de madeira em Moju, Pará. Rev. Ceres, v. 63, n. 4, p. 427435, 2016.

KAERCHER, N.A. A geografia crítica - alguns obstáculos e questões a enfrentar no ensino aprendizagem de geografia. Boletim gaúcho de geografia. Porto Alegre: AGB, 2002.

KRZYSCZAK, F.R. As diferentes concepções de meio ambiente e suas visões. Revista de Educação do IDEAU, v. 11, n. 23, p. 1-17, 2016.

LANDIM-NETO, F.O.; DIAS, F.H.L. Mapas Mentais E a Construção De Um Ensino De Geografia Significativo: Algumas Reflexões. Revista Eletrônica Geoaraguaia, v. 1, n. 1, p. 1-12, 2011.

MARIA, E.C.; ZANON, A.M. A educação ambiental a partir de um olhar freiriano. Rev. eletrônica Mestr. Educ. Ambient., 2012.

MENDES, J.C.R.; SAMPAIO, K.L.S.; MURIBECA, A.J.B.; MARTINS-JÚNIOR, A.S.; TAVARES-MARTINS, A.C.C. Trilha ecológica como estratégia para educação ambiental em Salvaterra, Pará, Brasil. Educação Ambiental em Ação, ano 15, n. 58, 2016.

MENGHINI, F.B. A trilha interpretativa como recurso pedagógico: Caminhos traçados para a educação ambiental. Dissertação de mestrado, Santa Catarina. 2005. 
MONTEIRO, I.F.C.; MONTEIRO, P.D.E.B.S.C.O. A educação ambiental e as representações sociais dos professores da rede pública no ensino fundamental. Revista Brasileira de Educação Ambiental, v. 12, n. 1, p. 165-176, 2017.

MOREIRA, M.A. Abandono da narrativa, ensino centrado no aluno e aprender a aprender criticamente. Ensino, Saúde e Ambiente, v. 4, n. 1, p. 2-17, 2011.

NELSON, S.P. Uso Público nas Unidades de Conservação. In: CASES, M.O. (Org.). Gestão de unidades de conservação: compartilhando uma experiência de capacitação. Brasília, 2012. p. 215-237.

OLIVEIRA, N.S.; CEARENSE, C.P. Mapas mentais - uma forma de representar a compreensão e interpretação do lugar. UFPR. Curitiba-Pr, 2006.

OLIVEIRA, N.A.S. A educação ambiental e a percepção fenomenológica, através de mapas mentais. Revista eletrônica do Mestrado em educação ambiental. Minas Gerais. Vol. 16, Jan/Jun. 2006.

PEREIRA, S.S.; CURI, R.C. Meio Ambiente, Impacto Ambiental e Desenvolvimento Sustentável: Conceituações Teóricas sobre o Despertar da Consciência Ambiental. REUNIR - Revista de Administração, Contabilidade e Sustentabilidade, v. 2, n. 4, p. 35-57, 2012.

PINHEIRO, B.R.A.; SOARES, A.S.; AZEVEDO, F.F. A relação homemnatureza e a práxis do turismo: um (re)encontro para a preservação. Revista Brasileira de Ecoturismo, v. 3, n. 2, p. 331 340, 2010.

PINHEIRO, L.B.C.; LIMA, F.S.; ROCHA, T.T.; TAVARES-MARTINS, A.C.C. Ressignificação das concepções de natureza, meio ambiente e educação ambiental através de uma trilha ecológica. Revista Brasileira de Educação Ambiental, v. 11, n. 1, p. 196-214, 2016.

REIGOTA, M. O que é educação ambiental. São Paulo: Brasiliense, 2006. Coleção primeiros passos. 62p.

SANTOS, J.A.E.; IMBERNON, R.A.L. A concepção sobre "natureza" e "meio ambiente" para distintos atores sociais. Terra e Didática, v. 10, n. 1, p. 151159, 2014.

SANTOS, J.E.; SATO, M. A contribuição da Educação Ambiental à esperança de Pandora. São Carlos: Rima, 2002. 624 p.

SAUVÉ, L. Educação Ambiental: Possibilidades e Limitações. Educação e pesquisa, v. 31, n. 2, p. 317-322, 2005.

SILVA, A.F. O jogo didático como instrumento para séries finais do ensino fundamental: proposta para trabalhar os temas ambientes e diversidade. Revista Brasileira de Educação Ambiental, v. 11, n. 5, p. 167-183, 2016.

SILVA, M.M.; NETTO, T.A.; AZEVEDO L.F.; SCARTON, L.P.; HILLIG, C. Trilha ecológica como prática de educação ambiental. Revista Eletrônica em Gestão, Educação e Tecnologia Ambiental, v. 5, n. 5, p. 705 - 719, 2012. 
SILVA, N.F.; RUFFINO, P.H.P. Educação ambiental crítica para a conservação da biodiversidade da fauna silvestre: uma ação participativa junto ao Projeto Flor da Idade, Flor da Cidade (Itirapina-São Paulo). Relatos de experiência, v. 97, n. 247, p. 637-656, 2016.

SORRENTINO, M.; TRAJBER, R. Políticas de Educação Ambiental do Órgão Gestor. Brasília, 2007.

SOUSA L.F. Das imagens aos mapas mentais: uma proposta de Entendimento das percepções presentes em escolas Ribeirinhas de porto velho. ENPEG, Porto Alegre, 2009.

SOUZA, V.T.; RAGGI, F.A.S.; FRANCELINO, A.S.S.; FIGUEIRÓ, R.; RODRIGUES, D.C.G.A.; SOARES, A.R. Trilhas interpretativas como instrumento de educação ambiental. Ensino Saúde e Ambiente, v. 5, n. 2, p. 294-304, 2012.

VENTURIERI, B.; SANTANA, A. Concepções sobre meio ambiente de alunos do ensino fundamental em Belém-PA: estudo de caso com a E. E. E. F. M. prof. Gomes Moreira Junior. Revista Brasileira de Educação Ambiental, v. 11, n. 1, p. 234-245, 2016.

WOLLMANN, E.M.; SOARES, F.A.A.; ILHA, P.V. As percepções de Educação Ambiental e Meio ambiente de professoras das séries finais e a influência destas em suas práticas docentes. Revista Brasileira de Pesquisa em Educação em Ciências, v. 15, n. 2, p. 387-405, 2015.

WUNDERLICH, A.C.; PINHEIRO, M.A.A.; RODRIGUES, A.M. T. Biologia do caranguejo-uçá, Ucides cordatus (Crustacea: Decapoda: Brachyura), na Baía da Babitonga, Santa Catarina, Brasil Alison. Revista Brasileira de Zoologia, v. 25, n. 2, p. 188-198, 2008. 